\title{
Valor social de la fotografía de guerra: Robert Capa en la Guerra civil española
}

\author{
Raquel CLAVERÍA LÓPEZ \\ rclaveria@hotmail.es
}

Recibido: 16/03/2015

Aceptado: 21/09/2015

\section{RESUMEN}

A partir del análisis de las relaciones entre sociología, fotografía y documentación se realiza un recorrido por algunas de las principales fotografías realizadas por Robert Capa durante la Guerra civil española. Palabras clave: Fotografía, Sociología, Documentación social, Análisis de la imagen.

\section{Analyzing war photography: Robert Capa in the Spanish Civil War}

\section{ABSTRACT}

Analysis of the relationship between photography and sociology to analyse the work of Robert Capa in the Spanish civil war

Keywords: Photography, Sociology, Social Documentation, Image analysis.

\section{Referencia normalizada}

Clavería López, R. (2015). "Valor social de la fotografía de guerra: Robert Capa en la Guerra civil española”. Documentación de las Ciencias de la Información, Vol. 38: páginas. 223-244 
"La fotografía es una herramienta para tratar con cosas que todos conocen pero a las que nadie presta atención. Mis fotografías pretenden representar algo que ustedes no ven".

Emmet Gowin

\section{EL NACIMIENTO DE LA FOTOGRAFÍA}

La fotografía es considerada un arte, de hecho según la definición que nos ofrece el Diccionario de la Real Academia Española, fotografía es el "arte de fijar y reproducir por medio de reacciones químicas, en superficies convenientemente preparadas, las imágenes recogidas en el fondo de una cámara oscura”. Sin embargo, en el presente escrito no vamos a tratar el valor artístico de las imágenes, a pesar de que es muy interesante, sino el valor social de la fotografía, es decir, la utilidad que esta ha tenido en el desarrollo de la sociedad del siglo XX.

La fotografía nació en Francia en la primera mitad del siglo XIX, al igual que la Sociología. Desde el primer momento causó sensación, pues como bien explica Riego (2001):

"La fotografía en tanto que nueva tecnología viene a superar las posibilidades de las técnicas de representación gráfica existentes hasta la fecha pero, como ocurre con cualquier nueva tecnología, su presencia añade una nueva cualidad a los sistemas ya en uso, las imágenes que produce no son fruto de la imaginación humana, sino reproducciones espontáneas de la realidad en la que el mérito del operador reside, precisamente, en su pericia para obtenerlas. (...) Las imágenes fotográficas tienen un certificado de veracidad que ninguna otra técnica puede representar (p. 299)”.

Aunque quizás sea Freund (2011) quien aporte una definición más cercana a la visión social que en esta investigación proponemos de la fotografía:

"Desde su nacimiento la fotografía forma parte de la vida cotidiana. Tan incorporada está a la vida social que, a fuerza de verla, nadie lo advierte. Uno de sus rasgos más característicos es la idéntica aceptación que recibe de todas las capas sociales. (...) Ahí reside su gran importancia política. (...) Al mismo tiempo, se ha vuelto para dicha sociedad un instrumento de primer orden. Su poder de reproducir exactamente la realidad externa (...) le presta un carácter documental y la presenta como el procedimiento de reproducir más fiel y más imparcial de la vida social (p. 8)”

Ciertamente, uno de sus primeros usos fue el político, pues se utilizaron las imágenes para hacer propaganda electoral y tratar de reproducir un orden social deseado. Más adelante, ya entrados en el siglo XX, y tras la I Guerra Mundial, en Alemania surgen una serie de revistas ilustradas en las que los dibujos y los textos van dejando paso a las imágenes. Ahí es cuando oficialmente comienza el fotoperiodismo en 
Europa, aunque es justo decir que anteriormente algunos fotógrafos ya habían tratado de remover las conciencias sociales con sus imágenes, como por ejemplo Jacob Riis y su trabajo The other half, en el que da a conocer la desapacible vida de los inmigrantes del Nueva York de finales del siglo XIX, o Lewis Hine y Child Labours, en donde critica el trabajo infantil que todavía se daba en todo Estados Unidos a principios del siglo pasado. Sin embargo, será la creación de la revista norteamericana LIFE, en 1936, la que fragüe este tipo de informaciones y la que, en cierta medida, vaya conduciendo a sus fotógrafos, y a sus lectores, hacia un tipo de fotoperiodismo comprometido, hacia una fotografía documental que se encargue, como dice Rosa (2013) en el libro homenaje al fotoperiodista gallego José Cendón: “de hacer visible lo invisible, de contar lo no contado” (p. 7). Además, a partir de LIFE van apareciendo más y más revistas ilustradas que demandan fotografía social, como por ejemplo son la norteamericana Time o la francesa $\mathrm{Vu}$.

No debemos olvidar, por otro lado, que en esos primeros años del siglo pasado la industrialización permite que la técnica fotográfica mejore muchísimo, lo cual favorece, junto con la imprenta, a que prolifere el fotoperiodismo, pero también a que la gente de a pie comience a utilizar las cámaras para fines particulares tales como retratos familiares o turismo (Sontag, 2014). De hecho, Riego (2001) dice que:

“Cada vez se hace más evidente que las imágenes impresas han cumplido en nuestra cultura una función de transmisión rápida de información, sobre todo información técnica, en algunas situaciones en las que el texto escrito, a pesar de la versatilidad que ha logrado y el alto nivel que tiene en la transmisión de las ideas, las sensaciones o los hechos, es sin embargo, claramente insuficiente e inferior a la imagen (p.12)”

Uno de los primeros conflictos que se dio a conocer al mundo fue la Guerra Civil Española. Es cierto que, previamente, habían sido fotografiadas la Guerra de Crimea, la Guerra de Secesión Norteamericana y la I Guerra Mundial, pero la escasez de medios técnicos impidió recoger unas fotos de calidad en dichos conflictos bélicos; por ello se considera que la guerra española fue la primera en ser captada fielmente, además de que fue recogida de forma masiva debido a la gran cantidad de fotógrafos que se desplazaron para ser testigos de la contienda civil. A través de la labor de los fotorreporteros, el mundo conoció "de cerca” la crueldad de la guerra española. Ello propició a que muchos soldados extranjeros se uniesen a las Brigadas Internacionales que luchaban junto al bando republicano, así como que numerosas enfermeras llegasen a nuestro país para participar de la atención sanitaria que tanto se necesita en una situación de guerra.

Podemos decir sin miedo a equivocarnos que la Guerra Civil Española fue la precursora de la fotografía de denuncia social en los conflictos bélicos. Es especialmente a partir de entonces cuando se desarrolla un tipo de fotografía que demanda justicia social, que desea gritar al mundo el sufrimiento de determinadas poblaciones para así tratar de conseguir un cambio que propicie mejoras sociales. "Las fotografías no pueden crear una posición moral, pero sí consolidarla; y también contribuir a la 
construcción de una en cierne” (Sontag, 2014, p. 27). La guerra, la exclusión social y la pobreza pasan a un primer término en lo que a comunicación visual se refiere. El fotógrafo tiene ante sí diversos caminos a elegir, y uno de ellos es el de la fotografía documental.

\section{SOCIOLOGÍA VISUAL}

Como hemos dicho previamente, la fotografía viene de la mano de Louis Daguerre al mismo tiempo que la palabra Sociología es usada por vez primera por Auguste Comte, en el año 1939, y en el mismo país, Francia. Ambas surgen en un momento en el que la sociedad demanda explicaciones científicas; la voluntad de Dios, como respuesta a las preguntas que se formula la gente, ya no es suficiente y se necesita de la teoría y del empirismo. Ahí entran en juego la sociología, como ciencia que busca el conocimiento sobre la sociedad, y la fotografía como técnica que permite congelar un momento de la realidad para, posteriormente, ser analizado, pues "las fotografías procuran pruebas” (Sontag, 2014, p. 15).

No olvidemos que "la vista llega antes que la palabras. El niño mira y ve antes de hablar (...) La vista es la que establece nuestro lugar en el mundo circundante; explicamos ese mundo con palabras, pero las palabras nunca pueden anular el hecho de que estamos rodeados de él” (Berger, 2007). Con ello pretendemos hacer notar la importancia de las imágenes en la realidad social, ya no sólo porque estamos rodeados de ellas, sino porque biológicamente primero vemos, y más tarde leemos o hablamos.

El análisis de la imagen es lo que centra nuestros esfuerzos, pues se trata de la construcción social de lo visual (Bericat, 2011), aplicando así la perspectiva sociológica al estudio de las fotografías. Hay que insistir en que una imagen no es simplemente un trozo de realidad detenida en el tiempo, sino que es lo que esa estampa quiera comunicar al mundo, por lo tanto se trata de una herramienta de análisis social en tanto en cuanto a través de ella podemos volver al pasado e interpretarlo, y al mismo tiempo puede ser un medio de denuncia como bien explican De Miguel y Ponce (1994):

La foto puede ayudar a conocer y a denunciar situaciones sociales de hambre, violencia, carencias u opresión. La fotografía puede también colaborar a un conocimiento crítico de la sociedad. Es posible un conocimiento profundo a través de la emoción, y no sólo a través de los datos. Se trata, pues, de conocer para reformar, para cambiar. La foto se utiliza además en una tradición de diseñar pósters y collages que sirven de propaganda política y comercial. La fotografía puede ser utilizada para explicar visualmente los males sociales, los problemas de la sociedad. Permite describir comunidades, familias e incluso provocar la acción social (p. 86).

Para el análisis, el investigador social deberá saber distinguir tres tipos de fotografías: las fotografías ventana y las fotografías espejo, nombradas así por el fotógrafo y comisario de fotografía del MoMA de Nueva York entre los años 1962-1991, John Szarkowski (1978), y las fotografías regla o norma. ¿Qué representa cada uno de esos tipos? 
- Las fotografías ventana son aquellas que enseñan el mundo visible, las que muestran las cosas tal cual son para cualquier testigo que pase por allí, las que se asoman al mundo exterior, o como diría Szarkowski "through which the exterior world is explored in all its presence and reality" (1978). Es la realidad captada de manera fiel y exhausta, pero sin pretensiones de ofrecer una ideología, ni un pensamiento, ni una opinión.

- Las fotos espejo, por el contrario, son aquellas que desarrollan el pensamiento del autor. Éstas están cargadas de subjetividad e intencionalidad, pues pretenden conseguir hacer llegar al espectador el sentir del autor en el momento de la captura, ya que "aun cuando la producción de la imagen sea enteramente adjudicada al automatismo de la máquina, la toma sigue siendo una elección que involucra valores estéticos y éticos” (Bordieu, 2003, p. 18).

- Por último las fotos regla, también llamadas norma, son aquellas que quieren fomentar el control social; son producto de la fantasía, de lo irreal, y son mayormente empleadas políticamente para señalar cómo uno debe comportarse o actuar, qué está bien y qué mal, y también pretenden instaurar una norma idealizada. "Estas fotos no sólo tienen un significado, sino que producen significado” (De Miguel y Ponce, 1994, p. 90).

Todas las fotografías pertenecen a uno de estos tres tipos, si bien es cierto que a veces pueden combinarse las tres modalidades en una sola imagen, aunque eso sí, en proporciones distintas.

Por otro lado, debemos destacar la importancia de la mirada a la hora de realizar el análisis de las imágenes cuando se trata de hacer ciencia social. Se puede mirar rápido o lento, pero no se ve lo mismo. Cuando se hace un visionado rápido, el espectador reconoce un mensaje superfluo y se queda con él, sin profundizar más. Sin embargo, cuando el espectador contempla la fotografía, se detiene en ella, la analiza, observa cada detalle de la misma, lo que es obvio y lo que es sucinto, intenta entender el sentido de la imagen y la pretensión del autor; ahí empieza el conocimiento de la realidad social.

Según Del Valle (1999) la fotografía se ha relacionado, y se relaciona, con el mundo de tres maneras: de manera simbólica, epistémica y estética. Primeramente, simbólica porque la imagen desde siempre ha sido usada como mágica o religiosa. Buen ejemplo de ello son los iconos religiosos o las pinturas rupestres. Epistémica desde el momento en que informa visualmente de algo que sucede en el mundo y que gracias a la imagen puede, no solo servir de mera información, sino que además se puede llegar a investigar incluso aquellos aspectos que no sean visuales. Y estética en el sentido en que provoca emociones en el espectador, aunque por ser estética no quiere decir que tengan que ser sensaciones positivas o agradables, pues como veremos más adelante las fotografías también pueden generar sufrimiento, melancolía, rechazo, tristeza, dolor, etc.

Como sucedía con los tres tipos de fotografías (ventana, espejo y regla), los modos en que las imágenes se relacionan con la sociedad tampoco son excluyentes el uno con el otro. Sucede a menudo que una fotografía que en un principio tenía una fun- 
ción epistémica, por ejemplo, pase a tener una función simbólica y/o estética. Un ejemplo de esto sería la fotografía de Robert Capa (1936), en la que aparece un miliciano cayendo al suelo tras ser herido por disparos del bando nacional. Esa instantánea, en un primer momento, tenía las pretensiones de informar al mundo sobre lo que estaba aconteciendo en España, y de hecho cumplió con esa labor; sin embargo, con el paso de los años, se ha convertido en un icono, en un símbolo de la represión franquista y de la Guerra Civil Española. Esa imagen ha dado la vuelta al mundo y aparece en todos los libros de historia del siglo XX. Por ello, podemos juzgar que, efectivamente, ha traspasado su función meramente epistémica para llegar a ser símbolo, pero también para cumplir con una función estética en tanto en cuanto, al ser analizada, es imposible no admirarla profundamente y no caer en su belleza composicional, así como en la tristeza que proporciona toda fotografía de guerra.

\section{VALORES Y USOS DE LA FOTOGRAFÍA SOCIAL}

A la hora de comenzar a investigar con fotografías es necesario distinguir, como plantea Becker (1974), entre sociología visual, fotografía documental y fotoperiodismo. Veamos que la sociología visual puede acoger en su seno a las otras dos, pues es la encargada de enseñar a mirar para construir la realidad social y promover los cambios en los procesos de desigualdad social. Dicho esto, la verdadera diferencia está entre la fotografía documental y la periodística. La fotografía periodística, aunque puede serlo en determinadas ocasiones, no es fotografía documental per se, pues aunque su misión sea la comunicación, dar testimonio, siempre lo hace bajo la tutela de la ideología del medio en el que se publique, con lo cual es un tipo de trabajo fotográfico que puede ser tergiversado una vez llegue a la redacción. Por lo contrario, la fotografía documental es aquella que recoge un suceso con la intención de informar y enseñar al espectador, sin una plataforma que la lance, ni un ideario previo que la suscite. La fotografía documental es una simple y llana evidencia de la realidad del momento en que se toma la imagen, y la única "ideología" que puede haber tras ella es la del autor en su pretensión de mostrar al mundo lo que ve y lo que siente. Dicho esto, es fácil que a veces ambas puedan mezclarse, bien sea porque el medio en el que se van a reproducir no tenga una intención previa más que la información, bien sea porque pueda coincidir la intencionalidad del medio con la del fotógrafo.

En el trabajo con imágenes, el científico social puede tomar tres posiciones; como fotógrafo de la realidad social, esto es, tomando sus propias imágenes en función de la investigación que pretenda realizar. Así lo hizo, por ejemplo, el famoso sociólogo y fotógrafo Lewis Hine cuando retrató a los inmigrantes que llegaban a Nueva York, o cuando recriminó el trabajo infantil que todavía se daba en su país a principios del siglo XX (Freund, 2011). Y también Pierre Bordieu cuando inmortalizó la guerra de independencia en Argelia, definiendo él mismo su trabajo de esta manera: "en algunos casos yo hacía las fotografías para poder recordar, para poder describir después. En otros casos, era una forma de mirar" (2002).

También se puede optar por trabajar con fuentes secundarias, es decir, con fotografías de otros autores, obteniéndolas de la consulta de bases de datos, libros y revistas, 
páginas web, etc. De esta manera, el científico busca aquello que le interesa, pudiendo comparar autores y así elegir las imágenes que mejor se adapten a su estudio. Quizás el mejor ejemplo que podamos poner de este tipo de análisis con fotografías ajenas al investigador sea el monográfico "Sociología visual no 186” de Jesús M. de Miguel y Carmelo Pinto, profesores de sociología visual de la Universitat de Barcelona, en el que profundizan en la investigación social iniciada por el fotógrafo W. Eugene Smith en el pueblo extremeño de Deleitosa, hasta donde se desplazó el norteamericano para criticar el atraso al que se habían visto sometidos los pueblos de España tras la Guerra Civil.

Por último, también cabe la posibilidad de utilizar la técnica de la fotoelucidación, la cual consiste en enseñar las fotografías previamente elegidas a personas que reconocen la escena y que pueden elaborar un discurso coincidente con la temática de la investigación social, que por norma general lleva a otras informaciones muy interesantes que en un primer momento se desconocían y que, más tarde, pueden ser muy relevantes para el estudio. Con el estudio de Smith también se siguió este método cincuenta años más tarde, cuando Tino Soriano se desplazó a Deleitosa para comprobar la situación actual de la villa, mostrando a sus habitantes las fotos de Smith para reconocer personajes y escuchar historias que sirvieron de base para el proyecto que publicó en la revista Magazine del periódico catalán La Vanguardia.

\section{EL ANÁLISIS DE LA FOTOGRAFÍA DOCUMENTAL}

A lo largo de nuestra investigación hemos encontrado distintas propuestas sobre cómo realizar el análisis de la fotografía documental. Por supuesto todas ellas eran muy válidas e interesantes, sin embargo nos ha parecido acorde con nuestro estudio tomar como referencia la que propone el profesor riojano Félix del Valle en su artículo “Dimensión documental de la fotografía” (1999) quien afirma:

"En la consideración de la fotografía como objeto de análisis será preciso estudiar todos sus atributos, entendiendo este término como cualquier tipo de característica, componente o propiedad del objeto que pueda ser representado. (...) Los atributos no se limitan a las características puramente visuales e incluyen también respuestas cognitivas, afectivas o interpretativas y otras que describen sus características espaciales, semánticas, simbólicas o emocionales".

Cuando se analizan fotografías documentales hay que hacerlo teniendo en cuenta sus atributos morfológicos, sus atributos de origen o biográficos, los temáticos o de contenido y los atributos relacionales. Los morfológicos son aquellos referentes a la técnica usada para captar la imagen y para conservarla, tales como químicos usados en su revelado, soporte empleado, conservación, etc. Los atributos de origen, o biográficos, son los que se refieren al autor de la fotografía, como por ejemplo su nombre, su formación, dónde publica las imágenes, etc. Los atributos temáticos son los refe- 
rentes al mensaje de la fotografía; aquello que dice y la manera en que lo dice. Y, finalmente, los atributos relacionales son aquellos que permiten que la imagen objeto de análisis se relacione con otras imágenes o con otro tipo de documentos debido al tema central de análisis de la fotografía.

Los atributos morfológicos y biográficos son objetivos y directos. Conseguir esa información suele ser fácil, aunque no es la más necesaria en el análisis de la fotografía documental, para ser sinceros. Los atributos temáticos sí son verdaderamente importantes a lo hora de la investigación social a través de las fotografías, pues es donde radica el mensaje que la imagen pretende ofrecer al espectador.

Ciertamente, una fotografía puede tener diversas lecturas, por esa razón el investigador deberá tratar con sumo cuidado el material y deberá saber dar sus pasos sin posibilidad de error. Las imágenes siempre ofrecen un mensaje obvio, denotado, entendible para todos por igual. Es en la denotación cuando se puede hacer una lectura descriptiva de la imagen aplicando las $6 \mathrm{~W}$ : ¿Quién? ¿Qué? ¿Dónde? ¿Cuándo? ¿Por qué? ¿Cómo? Pero lo importante en el análisis de las fotografías es el mensaje connotado, el simbólico, el que no se ve a simple vista. Es este el que se ha de tratar con delicadeza, siendo exhaustivamente estudiado e investigado. Llegados a este punto, el investigador social debe elegir entre dos opciones no excluyentes: Averiguar qué quiere decir el autor de la fotografía a través de su imagen o buscar en la instantánea lo que ésta dice. En esta opción, también se deberá distinguir entre lo que dice la imagen del contexto en el que es reproducida, o lo que dice la imagen sobre el espectador a la que va dirigida.

En cuanto a los atributos relacionales, tampoco debemos perderlos de vista, pues normalmente las imágenes forman parte de una historia que quiere ser contada, bien sea redactada en texto acompañando a la fotografía, bien sea a través de una relación de instantáneas que pretenden explicar una historia (reportaje). Lo que sucede en estos casos, es que debemos ir más allá del mensaje de la sola imagen.

Cuando un texto acompaña a la fotografía se producen efectos lingüísticos y narrativos. Lingüísticos porque lo escrito amplía la información que, en un principio, ofrece la imagen, guiando al lector y ofreciéndole una explicación de lo que se ve y de lo que no se ve; y narrativos porque el escrito construye la historia de la fotografía, situándola en un espacio-tiempo concreto, y resumiendo los hechos que se representan en la instantánea. Obviamente, el texto es altamente informativo y constituye una parte importante de la comprensión de la imagen, pero también es muy peligroso, pues recordemos lo que comentamos páginas atrás, y es que el medio en el que sea reproducida la imagen puede moldear la información a su antojo, no siendo del todo veraz o realista. $\mathrm{O}$ en otra situación, a veces los textos se escriben cuando ya ha pasado tiempo de la historia que la fotografía pretendía mostrar, e incluso son redactados por personas que nada tienen que ver con ella, entonces puede suceder que el texto se convierta en una trampa, pues no ofrecerá datos exactos.

Los reportajes fotográficos son más fiables. Todos sabemos que sacar una sola imagen de algo es casi imposible. Normalmente cuando fotografiamos algo hacemos varios disparos, teniendo así una historia relativamente completa de los hechos. Al final, solemos quedarnos con aquella fotografía que nos parece mejor por la razón que 
sea, pero tenemos en nuestro archivo la serie completa para, si lo necesitamos en algún momento, poder volver atrás y ampliar la información de la imagen seleccionada. Es normal que la memoria no recoja toda la información que ha sido recogida por la vista, pero la cámara sí lo hace. A través de su lente recoge cada detalle que puede encuadrar su objetivo, sin olvidar nada y sin menospreciar ningún dato. Por esa razón, la cámara, y por tanto la fotografía, se convierte en una buena aliada para la investigación social.

\section{ANÁLISIS DE IMÁGENES DE GUERRA}

Robert Capa, o lo que es lo mismo, Endre Friedmann, es uno de los fotógrafos más célebres del siglo XX. Nace en Budapest (Hungría) en 1913 y con 18 años decide irse a vivir a Berlín (Alemania) buscando cumplir su sueño de ser escritor. Allí consigue un empleo como fotógrafo, lo que hace que poco a poco vaya alejando de sí la idea de convertirse en novelista, pues se enamora de la profesión fotográfica. Debido al auge del nazismo, y la consiguiente persecución de los judíos, en 1933 ha de trasladarse a París (Francia) en donde junto con su compañera, también fotógrafa, Gerda Taro, adoptan un seudónimo para poder vender sus fotos. Cápa, en húngaro, significa tiburón, y es su apodo cuando es niño. Además, Frank Capra es un afamado director de cine americano de la época, y el similar sonido hace que a Friedmann le parezca ideal, pues considera que un nombre más americano le ayudará a lanzar su profesión, y no se equivoca, pues desde entonces se le hace mucho más fácil vender sus instantáneas, convirtiéndose así en un célebre fotoperiodista de guerra.

En 1936 Capa viaja a España para fotografiar la contienda civil y consigue vender sus fotos a la revista francesa $V u$. Las instantáneas se publican a modo de reportaje continuo, número tras número, en la revista, aunque de todas ellas es una la que mayormente capta la atención del mundo. Se trata de "Muerte de un miliciano", fotografía que fue tomada en el frente de Córdoba en septiembre de 1936.

"Muerte de un miliciano" (fotografía 1) ha sido una fotografía ampliamente analizada por especialistas en imagen, sociología, documentalismo y periodismo. Su importancia radica, además de en el valor informativo que tuvo en el momento en que se tomó, en el símbolo en que se convirtió, pues como bien se señala Serrano (1987) las imágenes de Capa:

"No son las de un observador indiferente, sino las de un informador comprometido. (...) La actividad fotográfica de Capa en España es de otra índole: sus fotos están destinadas a la opinión internacional, por el intermediario de la prensa; son el producto de la mirada de un fotógrafo identificado cuya labor pretende ser explícitamente informativa. (...) Suyas son las principales fotos que recorren en el tiempo y en el espacio todo el acontecimiento. (...) La guerra civil parece haber entrado en las retinas de los millones de lectores de las publicaciones gráficas del mundo entero. (...) La guerra civil es en este sentido el primer gran acontecimiento mediático de la historia contemporánea. Y lo es por la labor obstinada y persistente de un Robert Capa, entre otros pocos, 
para quienes esa guerra no era una guerra cualquiera, sino un combate propio, en el que actuaba directamente con el arma de su cámara y el riesgo de su vida. Algunas fotos de la guerra civil firmadas por Capa han dado la vuelta al mundo. Son pocas y se han convertido en las de siempre. (p. 24)”

Analizando la imagen con las directrices expuestas anteriormente, observamos que estamos ante una fotografía ventana, pues vemos que el autor ha captado fielmente la realidad, ya que recoge el momento exacto en el que un miliciano es abatido por el fuego enemigo, sin embargo, también podemos añadir que tiene un considerable componente de fotografía espejo, pues Capa, al seleccionar el encuadre, está eligiendo aquello que rodea al personaje de la fotografía, con lo cual se adivina una cierta intencionalidad, un interés en mostrar al mundo la realidad de la guerra, la soledad que en realidad la rodea. Además, su principal mensaje es de tipo epistémico, pues lo único que en un principio pretende el fotógrafo es dar a conocer al mundo la barbarie de la guerra española, aunque como bien hemos dicho el autor logra convertirla, gracias a su destreza, en un símbolo de la guerra civil española y de la fotografía de guerra en general, pues esta imagen es recogida en casi todos los libros de historia y de fotografía de guerra. También se puede decir que tiene un cierto componente estético, pues genera ciertos sentimientos al verla. Cuando la tenemos delante no podemos dejar de pensar en la tristeza de la guerra, en la sangre derramada ni en las lágrimas vertidas por culpa del mal entendimiento y de la crueldad de los seres humanos.

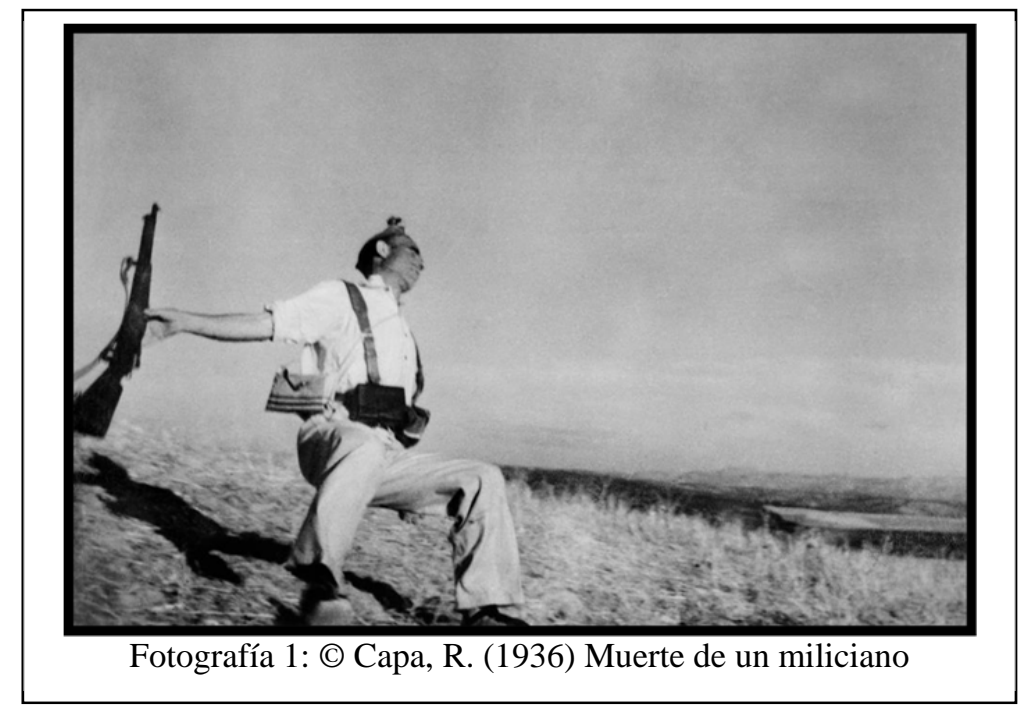

En cuanto a sus atributos temáticos, lo que esta instantánea pretende trasladar al mundo, una vez más, es la crudeza de la guerra. Al captar el momento del abatimiento del miliciano, Capa pretende hacer llegar a todo aquel que vea la imagen la crueldad de la guerra. La guerra no es algo ya de lo que hablan algunos pero nadie ve; con sus 
imágenes hace partícipe al mundo de ella. Con esta imagen se retrata el preciso instante en que aparece la muerte en el campo de batalla. En una guerra no hay más defensa para un soldado que las armas, pero también son las armas las que terminan con la vida de los soldados, lo cual es un sin sentido en sí mismo, y eso es lo que pretende retratar Capa en esta imagen, pues a pesar de que el miliciano cuenta con un rifle, eso no le vale de nada, pues termina perdiendo la vida por culpa del fuego enemigo.

Además, la guerra es soledad, ciertamente el soldado muere solo, nadie le acompaña en su última respiración. Vemos como Capa ha querido reflejar eso alejando del encuadre a cualquier otro soldado que, seguramente, estaría cerca del miliciano abatido. Además, si separamos la imagen en dos parte iguales, veremos que una mitad la ocupa el miliciano y la otra mitad la ocupa la nada, un paisaje vacío y desértico; indubitablemente un simbolismo de la soledad y de la tristeza.

Esta imagen está relacionada con muchas más de un amplio reportaje que hizo Capa sobre la Guerra Civil Española. De ahí surgió la duda de que fuese una imagen real, pues se encontraron ciertos clichés que apoyan la idea que ya algunos habían defendido, y es que parece ser que Capa y el soldado acordaron escenificar una muerte para que el fotógrafo pudiese tomar la imagen que tantas veces había visto ante él durante el tiempo que llevaba en la guerra, pero que todavía no había sido capaz de captar con su cámara. Ante esta situación, en esta investigación no es indistinto si la fotografía fue real o no, pues el mensaje de Capa sería el mismo, así como el momento y el escenario. De hecho, a pesar de la duda, sigue siendo la imagen que representa la Guerra Civil Española.

Previamente hemos indicado que Robert Capa retrató la guerra civil española a modo de reportaje. En las siguientes imágenes veremos cuáles fueron las demás componentes de su historia fotografiada. Asimismo, notaremos la relación que se establece entre ellas. Observaremos que hay un viaje en el tiempo y en la realidad. Sus fotografías caminan desde la calidez y la luz del verano de 1936 al frío angustioso de la batalla de Teruel en 1938. Las luces se han convertido en sombras, el calor en frío, las cabezas despejadas en casos gruesos y pesados, las sonrisas en miedo; ciertamente el "paseo" fotográfico de Capa, además de informativo, simboliza el crecimiento de la desesperanza de los españoles que ven que la guerra dura más de lo deseado (Serrano, 1987).

La presente instantánea (fotografía 2) muestra a una pareja de republicanos en actitud alegre y cariñosa. Se trata, pues, de una fotografía ventana, pues la realidad es la que está captada en la imagen. Aparentemente no hay un componente espejo en ella, aunque es verdad que tras la II Guerra Mundial se estableció un género fotográfico que constaba en captar momentos felices, cosas que la gente quisiese ver y que les permitiesen olvidar las penas que le rodeaban. Así pues, esta imagen puede tener un poco de intención, tratando de dar una visión menos cruel de la guerra; además no olvidemos que es una fotografía tomada muy al principio de la contienda, cuando todavía los españoles albergaban esperanzas de que el conflicto no se alargase demasiado en el tiempo. De ahí, quizás, el optimismo. 
Por otro lado, estamos ante una imagen que se relaciona con el mundo en modo estético, pues verdaderamente no cumple la labor de información, y sí aflora ciertos sentimientos; la escena causa gracia, simpatía hacia los dos personajes e, incluso, ternura.

En lo que a sus atributos se refiere, temáticamente se muestra una versión más amable de la guerra, en donde a pesar de las circunstancias el amor aflora, ofreciendo así un mensaje optimista a los receptores. La pareja protagonista de la imagen ostenta todo el peso de la escena, casi al 50\% de protagonismo, pues el hombre pesa un poco más en la fotografía gracias a sus gestos de tocarle la cara a la mujer y de inclinarse, ligeramente, sobre ella. Además, es importante en la escena la mitad inferior, pues ahí están claramente observando al espectador el casco de guerra y el arma, para que no olvidemos que, a pesar de la amabilidad de la imagen, la guerra existe y se hace palpable aún en momentos románticos.

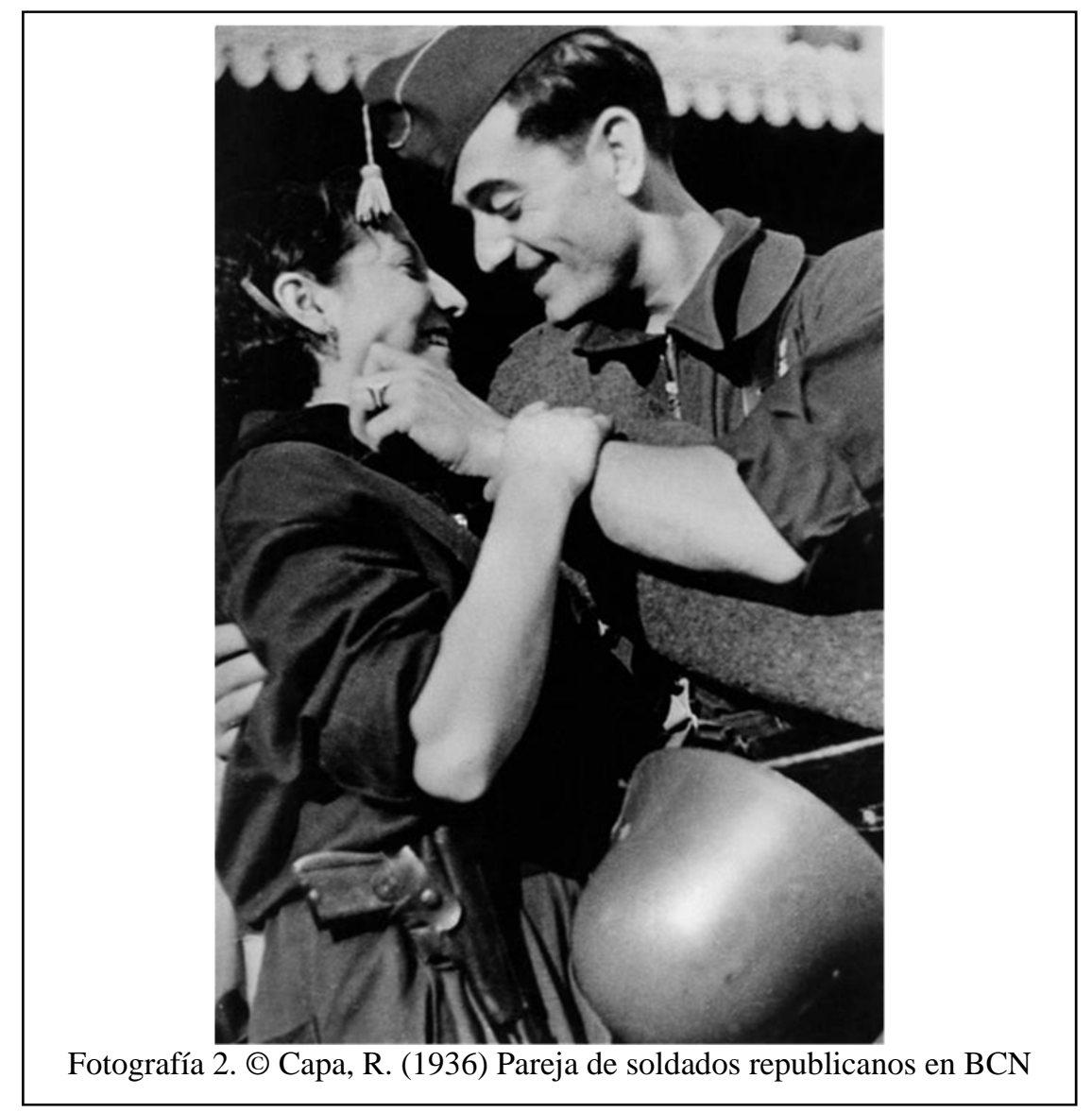


En cuanto a los atributos relacionales, iremos viendo a lo largo del reportaje que esta imagen toma mayor relevancia en grupo, pues simbolizará el comienzo inocente de una guerra que se torna dura y fría. La pareja feliz representará la inocencia de aquellos que en los albores de la guerra esperaban un combate menos largo y cruel, aunque luego la realidad fue bien distinta.

La actual fotografía (fotografía 3) es de tipo ventana, pues se muestra la partida de los republicanos al frente aragonés, sin embargo el mensaje escrito en el vagón del tren la convierte también en imagen espejo, pues podemos estar seguros de que el autor elige retratar a esa parte del convoy con toda la intención. Ahí vemos escrita la famosa frase de la Unión de Hermanos Proletarios (UHP): "jurad sobre estas letras hermanos: antes morir que consentir tiranos”. Asimismo, consideramos que se relaciona con los receptores de un modo principalmente epistémico, dado que se informa de la partida al frente de unos soldados, aunque también tiene un componente estético en tanto en cuanto esta imagen se toma en Barcelona en agosto de 1936, cuando un grupo de soldados republicanos toma el tren para acudir a luchar al frente aragonés, en un momento histórico en que la Generalitat de Catalunya quiere ofrecer calma y tranquilidad a los catalanes, de ahí la idoneidad de esta imagen para ese cometido, pues contemplamos la alegría de los soldados que aún por entonces albergaban la esperanza de ganar la guerra.

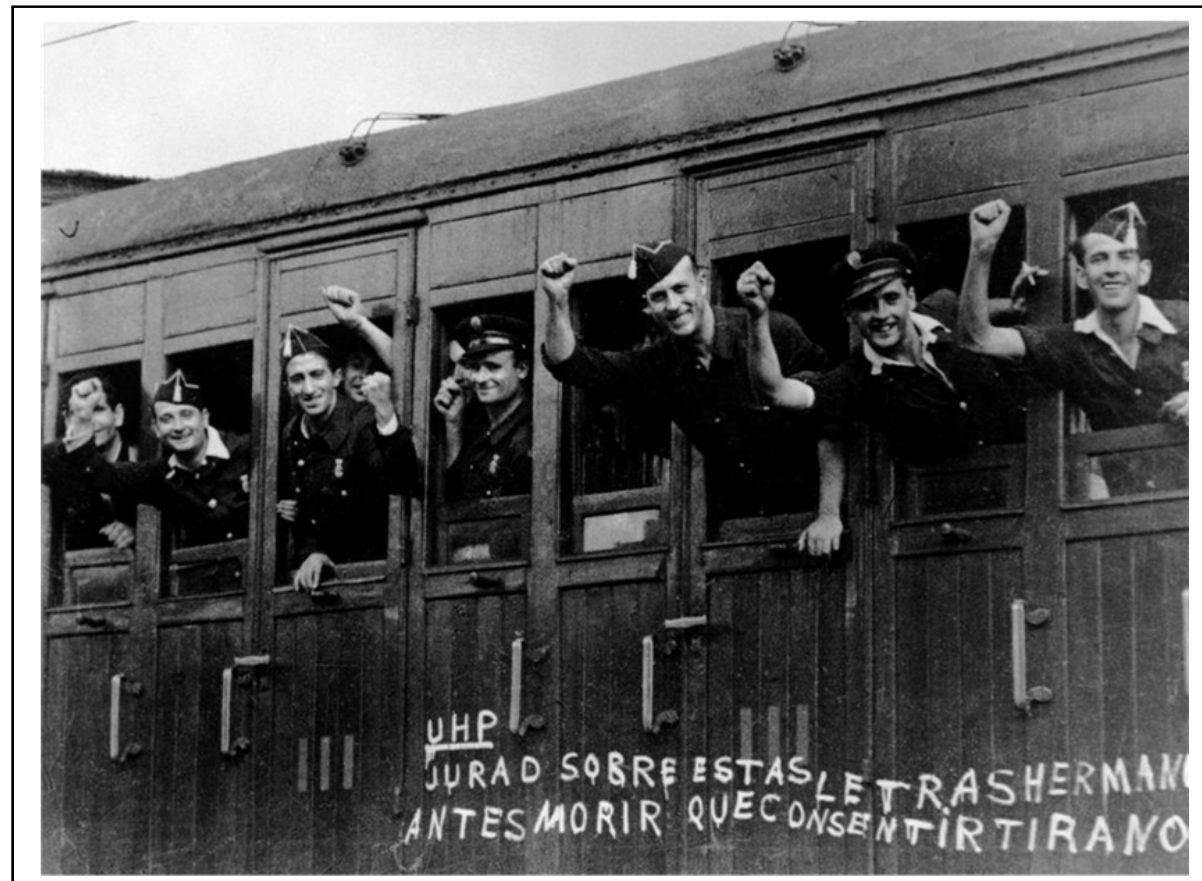

Fotografía 3. (C) Capa, R. (1936) Soldados que van al frente aragonés 
En lo que a los atributos temáticos se refiere, como en la anterior imagen, se muestra una alegría dentro de un contexto bélico. Los soldados están felices de acudir al frente a luchar por sus ideales y no dudan en mostrarse orgullosos, puño en alto, en el momento de la partida hacia la guerra. Se ven felices, alegres, orgullosos de participar de un momento histórico que seguro, en el momento de la captura, pensaron que terminaría de otro modo. Los valores que les dan la fuerza les acompaña en esa frase escrita en color blanco en el vagón (el blanco es el color de la inocencia). No hay lugar a dudas, son soldados republicanos. La escena se lee de abajo a arriba, primero la frase y luego los soldados, aunque son ellos quienes ostentan el peso de la escena, en sí, apoyados por la sentencia en blanco. Asimismo, la imagen va de izquierda a derecha, pues Capa pretende con ello dar un cierto movimiento a la escena, como si ya el tren estuviese partiendo, se van.... la guerra.

Como con la anterior escena, a medida que vayamos avanzando en las imágenes elegidas veremos la importancia de esta fotografía dentro del grupo. Representará, también, el principio inocente de lo que se convertirá en un largo calvario.

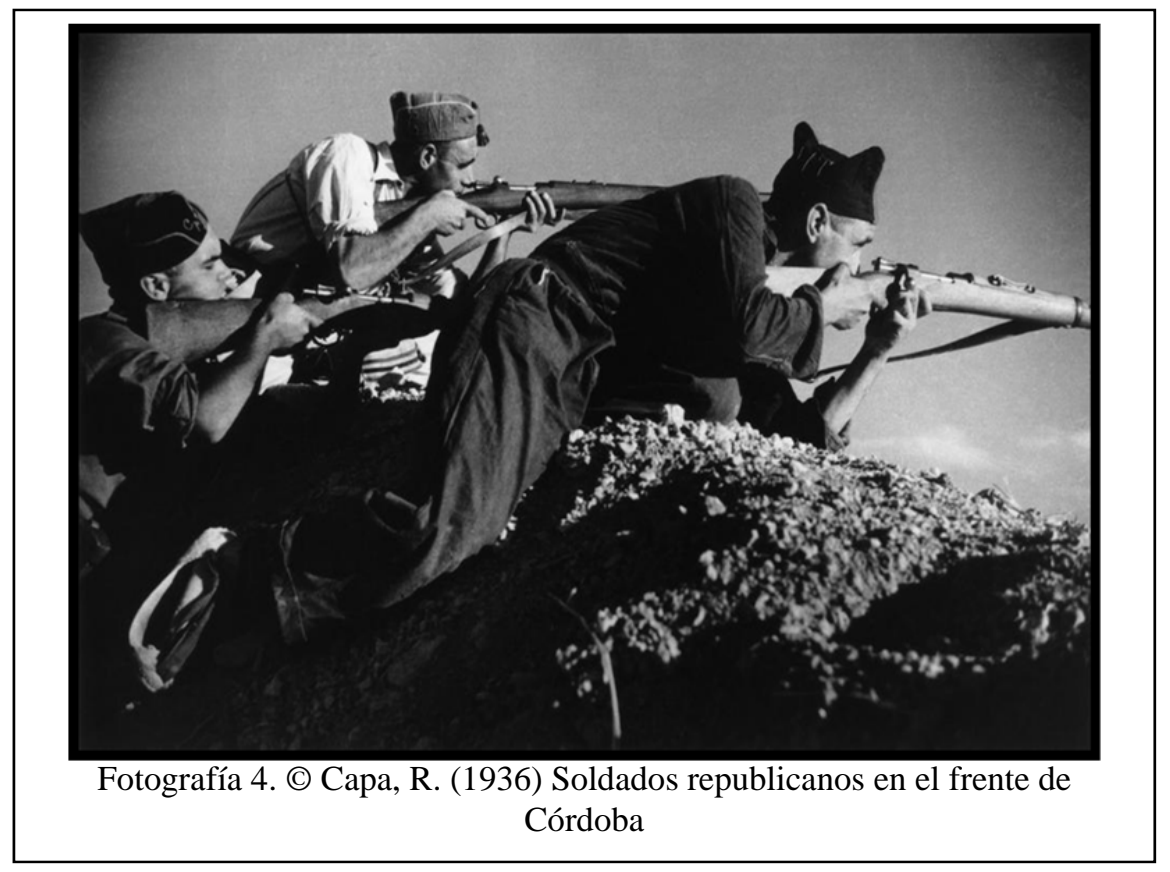

La escena de los Soldados republicanos en el frente de Córdoba (fotografía 4) ya muestra una imagen típica de guerra. Es una fotografía principalmente de tipo espejo, aunque con componente ventana, pues aunque el autor muestra al mundo un momento del combate, veremos en sus atributos temáticos cuál es la verdadera realidad de la imagen. En ella aparecen tres milicianos en posición de disparo al enemigo, con lo cual, también se trata de una imagen que llega al mundo de modo epistémico, con la intención de informar sobre la contienda civil. 
El peso de la escena lo tienen los tres soldados, cada uno a una altura y a una distancia diferente, algo que otorga profundidad a la imagen. Aparecen con la única compañía de sus armas, un fusil para cada uno de ellos, nada más. No van uniformados, únicamente les delata el gorro de miliciano. No tienen cascos para protegerse. Se arrastran por la tierra árida. Ocupan mayormente el cuadrante superior izquierdo de la imagen y enarbolan sus armas hacia el infinito, que queda a la derecha de la escena, donde están los enemigos. Se averigua aquí la intencionalidad de Capa, que es posicionarse del lado del bando republicano, ofreciendo su cámara para mostrar al mundo la desigualdad en la que luchan los republicanos y la valentía con que lo hacen.

Esta instantánea forma parte de la serie que Capa obtuvo el día en que fotografió "Muerte de un miliciano". Son los momentos previos a la famosa instantánea. Así pues, además de la importancia de la escena como parte del reportaje fotográfico completo que realizó Capa durante su estancia en España, también se destaca que sea una imagen de la secuencia completa de "Muerte de un miliciano".

Las siguientes imágenes (fotografías 5 y 6 ) las vamos a analizar juntas, pues muestran un mismo momento, una misma situación, en la vida de dos mujeres distintas. Se trata de dos fotografías tipo espejo, aunque con un considerable componente ventana, pues muestran la realidad, pero se ve claramente cómo el autor quiere hacer llegar a los espectadores la congoja y desesperación de los refugiados, quienes han de abandonar sus casas para tratar de protegerse de la guerra. Son dos mujeres que reflejan en sus caras la tristeza de la guerra.
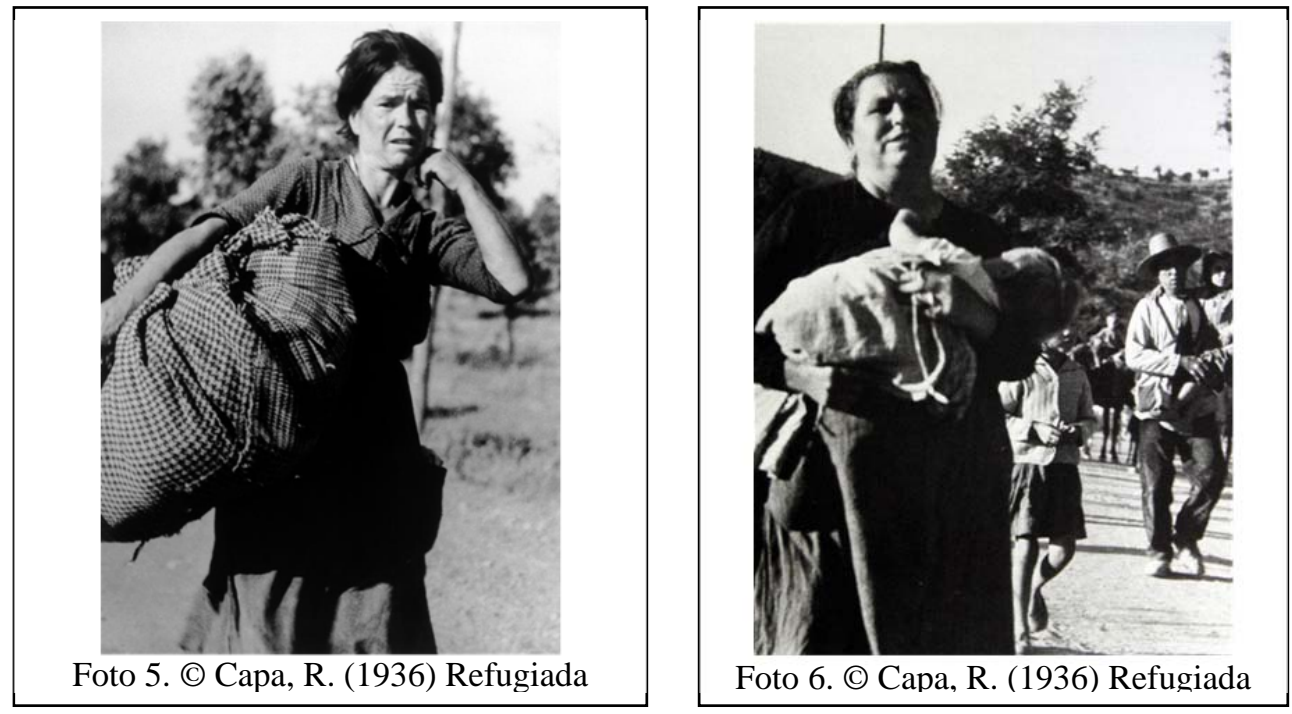

La primera mujer aparece sola, con un hatillo bajo su brazo en el que transporta escasas pertenencias. Se muestra insegura ante la cámara, desubicada; se lee en su faz preocupación y miedo. Ocupa el encuadre completo; sólo su desgracia es protagonista de la escena y Robert Capa lo da a conocer al mundo en un modo epistémico, informando a los espectadores de la situación de esta pobre mujer. 
La siguiente escena forma parte de la misma secuencia. En ella aparece otra mujer, toda vestida de luto y arrullando a un bebé vestidito de blanco (otra vez el color blanco) en sus brazos. Ocupa la mitad izquierda de la composición y tras ella aparecen, en la mitad derecha, más refugiados caminando hacia su incierto destino. A pesar de verse a más personas en la fotografía, el poder de la imagen lo ostenta la mujer que, a diferencia de la anterior, mira más directamente a la cámara, como clamando ayuda. El bebé que porta en sus brazos representa el futuro del pueblo español. Un futuro que va camino de lo desconocido, aunque ajeno a la verdadera situación debido a su corta edad y a la inocencia que le envuelve.

Como vemos, son dos imágenes que comparten los mismos atributos temáticos y relacionales. El lenguaje que emplea Capa para ambas escenas es el mismo, lo cual es obvio porque como autor es el suyo propio, la manera en que él quiere hacer llegar su mensaje al mundo. En este caso, se trata de un mensaje de petición de ayuda, de mostrar al público qué sucede en España, cómo las personas han de abandonar sus casas por la guerra, en donde incluso los bebés y los niños se ven involucrados sin ser culpables de nada.

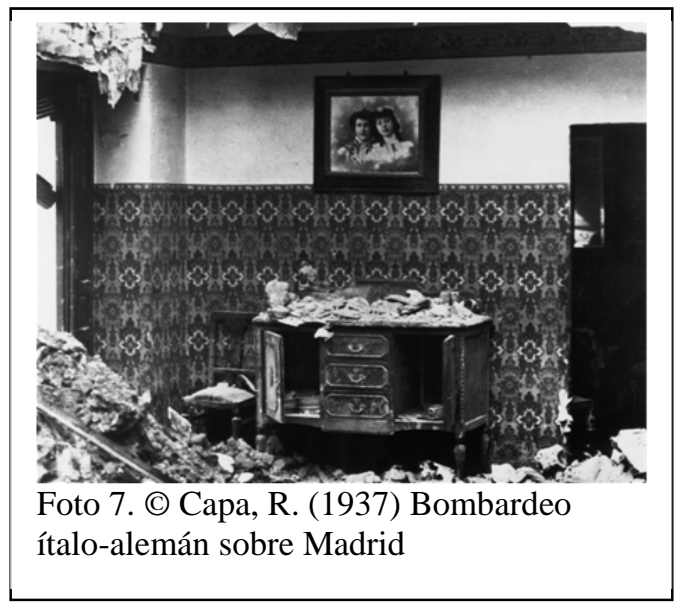

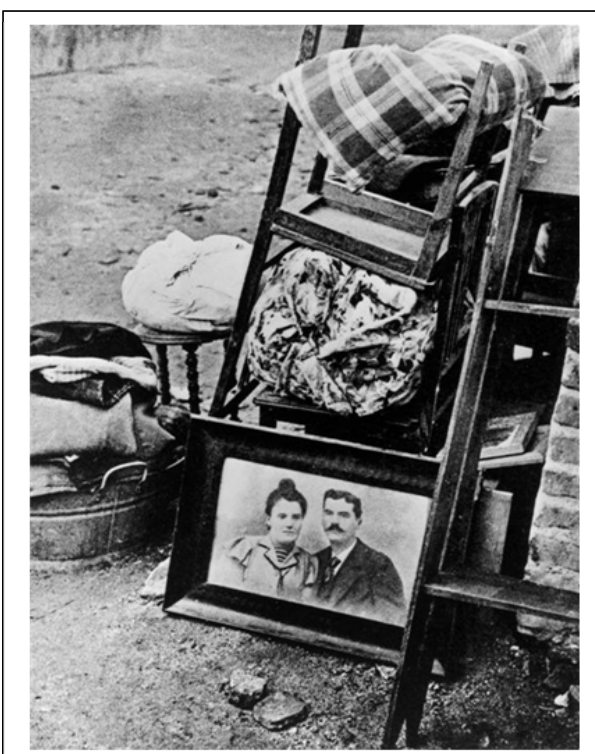

Foto 8. (c) Capa, R. (1937) Bombardeo ítalo-alemán sobre Madrid

Las presentes fotografías (fotografías 7 y 8) se introducen ya en los desastres directos de la guerra. Son fotografías espejo, con una proporción de ventana, en la que se enseña, en una de las imágenes, cómo ha quedado una de las habitaciones de una casa de Madrid tras los bombardeos ítalo-alemanes de 1937, y en la otra las pertenen- 
cias que han podido salvar algunos de los afectados por la ofensiva. Ambas imágenes introducen el factor humano indirecto en la escena, llevando al espectador a pensar qué habrá sido de esas personas que aparecen en los cuadros; por tanto, el modo en que se presentan esas imágenes al mundo es más estético que epistémico, pues aunque ciertamente ofrecen una información de un acontecimiento, también es verdad que las fotografías familiares aportan un fuerte cariz humano haciendo que surjan de su visionado sentimientos de preocupación, pena, tristeza, melancolía, etc. De hecho, la composición de la imagen 7 tiene una división superior-inferior en donde ambas, a pesar de la descompensación del peso del mueble con el cuadro familiar (ambos en el medio de la composición), tienen la misma fuerza visual; el espectador llega a establecer una comparación entre las ruinas de la casa y la imagen familiar, a pesar de lo pequeña de esta. Asimismo, resulta cuanto menos llamativo que tras los bombardeos en donde el edificio ha quedado en ruinas, permanezca en su sitio un simple cuadro testimonio de personas que tenían alguna relación con la casa devastada. Por su lado, la imagen 8 tiene una lectura de abajo a arriba. El retrato de la pareja tiene mucho peso en la escena y hace que el espectador si fije primero en ella y luego vaya subiendo la vista hasta alcanzar a ver las sillas y los hatillos que posiblemente reúnan las pertenencias de los afectados. Igualmente es atrayente que el cuadro familiar esté en el suelo, cubriéndose de polvo, pudiendo ser un reflejo simbólico de la realidad.

Ciertamente Capa usa a la perfección el lenguaje simbólico en la fotografía. Estas imágenes son fiel reflejo de ello. Sin necesidad de ver a ningún herido, a ninguna persona dañada, gracias a esos cuadros, la mente humana enseguida relaciona el conflicto vivido con lo que pueden haber sufrido los afectados. El valor de los cuadros es enormemente fuerte en las imágenes. El elemento humano hace que las escenas sean más sensibles, más tristes, más preocupantes. Capa no fotografía cualquier otra habitación destartalada; hizo la captura en aquella estancia en la que había un recuerdo de las personas que, posiblemente, vivían en esa casa o tenían algún ligamen con los que residían en ella. Era sabedor que esa imagen sin la presencia humana no tendría la misma fuerza visual. Lo mismo sucede con las pertenencias rescatadas del bombardeo; seguro que en el momento de la captura había diferentes bultos en la calle, pero eligió aquel en el que destacaba una imagen familiar que, nuevamente, introducía el elemento humano de manera indirecta.

Las imágenes que tratamos ahora (fotografías 9 y 10) muestran una parcela de la vida de los soldados del bando republicano. Ambas imágenes son fundamentalmente de tipo espejo ya que, una vez más, Capa deja fluir esa vena pro-republicana que caracteriza sus fotografías de la guerra civil, aunque existe en ellas el componente ventana, pues igualmente sirven de mera información al espectador.

El carácter de ambas instantáneas es fundamentalmente estético, como es habitual en la obra de Capa, pues vemos que pretenden generar ciertos sentimientos. ¿Cómo? En la imagen 9 aparecen unos soldados totalmente cubiertos, a los que no se les ve ni la cara, pues están mirando al lado opuesto del objetivo. Nosotros, los espectadores, no sabemos qué miran o qué buscan, y eso genera un cierto desconcierto en nosotros. ¿Miran algo, no quieren ser retratados, no saben que están siendo fotografiados? Capa se vale de esa no mirada (atributo temático) para captar la atención del público, que 
una y otra vez repasará la imagen para averiguar por qué los soldados están de espaldas a la cámara.

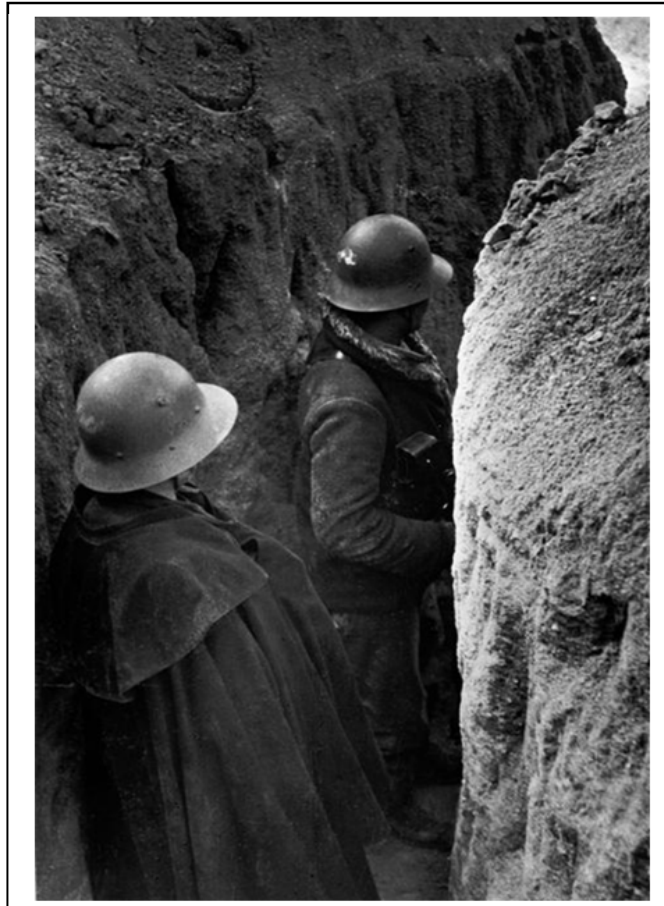

Foto 9. (C) Capa, R. (1937) Soldados en las trincheras

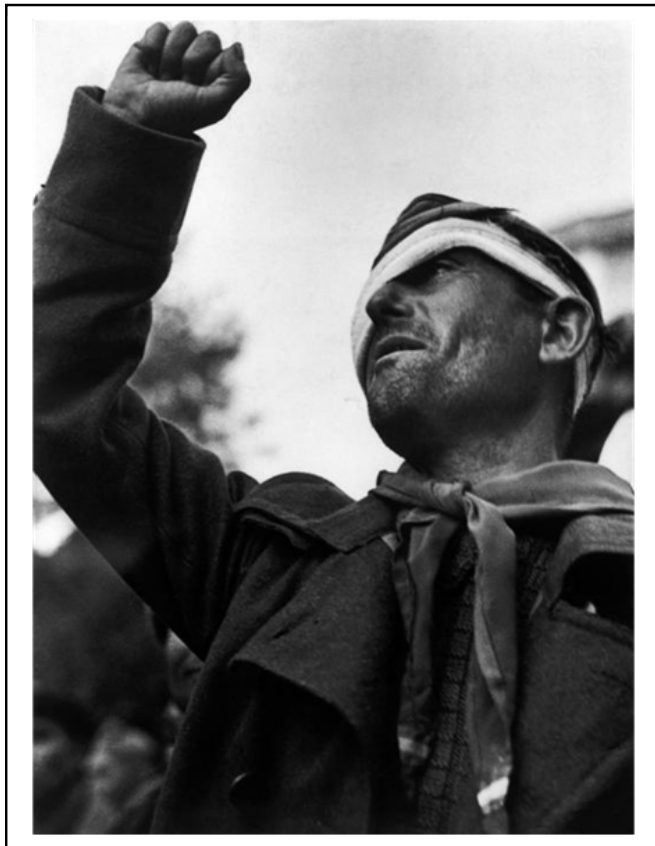

Foto 10. Capa, R. (1938) Saludo de un miliciano

En este caso, la composición de la fotografía va en diagonal, de la izquierda inferior a la derecha superior, creando profundidad, a pesar de ver que ella se sucede en una trinchera que, como vemos, es un espacio reducido. Ciertamente, las composiciones en diagonal otorgan profundidad de campo a las escenas, y de ello se vale Capa para proporcionar "aire" a la imagen.

La fotografía 10 no está relacionada directamente con la anterior, pues pertenecen a momentos distintos, aunque como hemos venido diciendo sí se relacionan en el contexto de la escenificación de la guerra civil que hizo Capa a través de sus capturas. En esta escena aparece un soldado herido levantando su puño ante el paso de las Brigadas Internacionales. Esta imagen recuerda a aquella que vimos anteriormente de los soldados que partían en tren hacia el frente aragonés, en donde salían izando su puño alegremente, sin saber lo que les espera y, al mismo tiempo, esperándolo todo. Sin embargo, a diferencia de aquella, aquí el miliciano ofrece una actitud más insegura, más miedosa, en donde parece que esté a punto de echarse a llorar. Además está herido, aunque no es una herida grave, pero quizás lo suficiente como para introducir el miedo en su cuerpo. 
El optimismo de la imagen que recordábamos antes ha dado paso a la desolación, como si el soldado ya supiese cuál va a ser el final de la contienda.

Como vemos, el fotógrafo en ambas capturas retrata a personajes que no miran a cámara, e incluso le dan la espalda. Pretende provocar con ello que el espectador se vea atrapado por el misterio de la imagen, por ver qué pasa, qué sucede, por qué unos no dan la cara y parece que estén mirando a un punto que no podemos ver, y por qué otro, a pesar de estar en una postura muy militante, tiene esa expresión de tristeza y desolación en su rostro. Lo que quiere Capa es que la persona que se encuentre con estas fotografías trate de buscar el sentido a las mismas, logrando reconocer en ellas el desamparo y el pesimismo que vivían los republicanos.

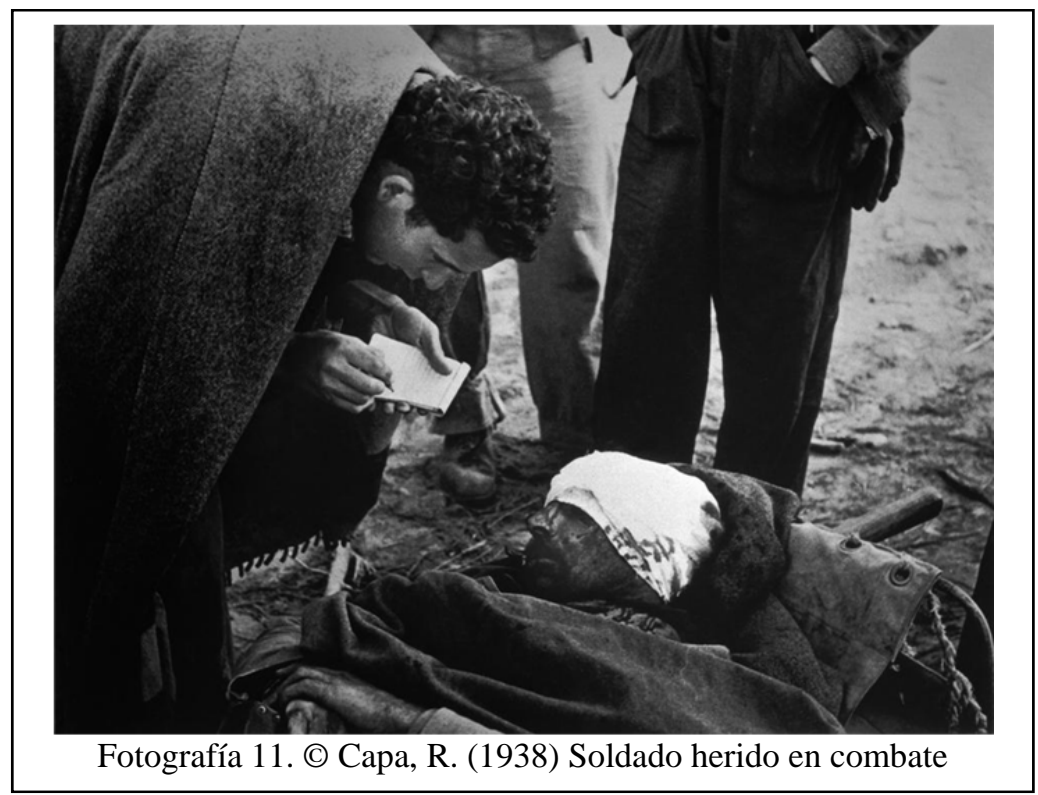

"Soldado herido en combate" (fotografía 11) es una fotografía espejo, en donde el autor expone la crudeza de la realidad de la guerra. Obviamente por ello también es una imagen de tipo ventana, pues es informativa de una realidad tal cual sucede, pero vemos que su lenguaje, como toda la creación de Robert Capa, está cargado de subjetividad e intención. También, como estamos viendo en el resto de imágenes, tiene un modo estético-epistémico, pues además de la información que ofrece no podemos obviar las emociones que provoca su visionado.

Los atributos temáticos que usa el autor son muy directos en esta fotografía: la composición de la misma hace que la atención del espectador recaiga directamente sobre el herido, más concretamente sobre su cara cubierta de sangre. Las figuras en vertical y la diagonal que describe el cuerpo del compañero de batalla llevan directamente al soldado lesionado, que permanece en posición de difunto (manos cruzadas sobre el abdomen). Es importante, también, el momento en que el compañero, incli- 
nándose sobre él, anota en una libreta sus últimas voluntades. Además todo ello sucede mientras dos personas permanecen impasibles ante la escena. La simbología es muy obvia: la sociedad que permanece invariable ante los desastres de una guerra que provoca muertes. Capa está retratando una realidad y, a la vez, está lanzando un grito de ayuda.

En relación con el resto de imágenes, vemos como nuevamente el optimismo de las primeras escenas ha dado paso a la muerte inminente. Ya no hay risas, ya no hay miedo, ni destrucción, ni tan siquiera hay lágrimas; ahora hay muerte. La guerra ha ido evolucionando en el sentido lógico, si se puede decir de esa manera, pero no de la forma esperada por aquellos primeros retratados por Capa.

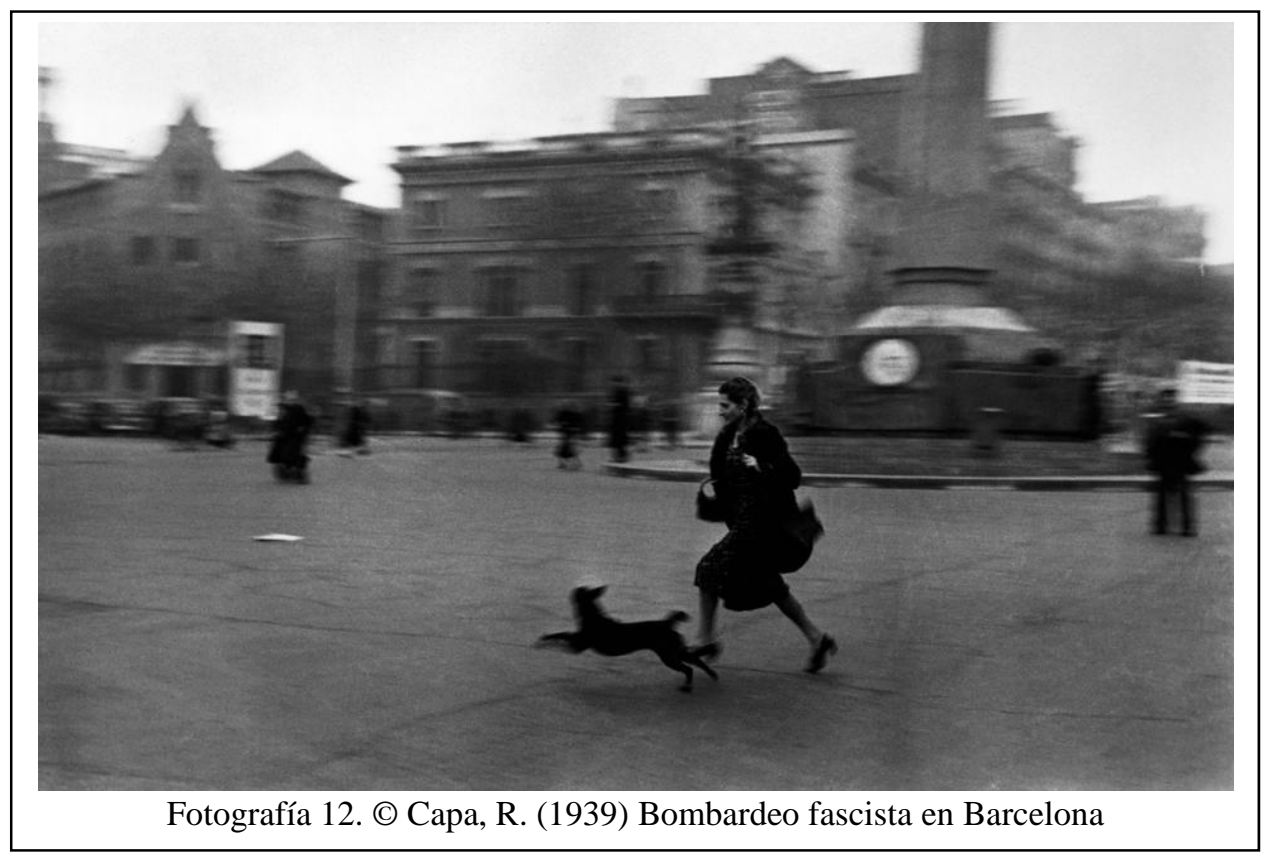

La última escena elegida (fotografía 12) sucede en Barcelona, durante el aviso del bombardeo sobre la ciudad. Se trata de una fotografía mayormente de tipo ventana (informativa) pero con un cierto componente espejo que lo averiguamos gracias al personaje del perro y al movimiento de la cámara.

En cuanto al modo en que se da a conocer a la sociedad, es muy epistémico pero también tiene una parte estética, pues la escena ofrece al público que se detenga en ella un cierto miedo de pensar en verse en la misma situación. Las huidas crean en nosotros sensaciones diversas y, en este caso, eso lo apoya Capa con el movimiento de la cámara a la hora de captar la escena, pues ello provoca en el espectador sensación de prisa, de nerviosismo. Ya que esas emociones no se pueden captar en una instantánea, el autor se apoya en esa técnica fotográfica para imprimirla en la escena. 
Los atributos temáticos son bastante obvios. Esta imagen ha sido una de las más famosas de la guerra civil, y es que, además de la técnica para enfatizar la prisa de la señora en buscar un refugio para protegerse durante el bombardeo, aparece un personaje animal, un perro que huye del bombardeo corriendo al lado de la mujer, incluso avanzando el paso de esta, como si hasta los animales se diesen cuenta de la situación de desamparo que vivía la población barcelonesa en esos días. Asimismo es importante el hecho de que ambos personajes van de negro (el color del luto en nuestra cultura), al igual que el resto de los presentes que se intuyen en la escena, pues aunque no se ven claramente sí se adivina que son personas.

A lo largo de las imágenes seleccionadas para tratar sobre el valor de la fotografía de Capa como una labor social, hemos visto cómo ha ido cambiando el fondo de la situación retratada, pues como se ha indicado en el análisis de cada imagen, el autor pasó de unos principios más animosos, en donde incluso había fotografías de momentos felices a pesar del inicio de una guerra, a situaciones más angustiosas en donde aparece la muerte.

\section{BIBLIOGRAFÍA}

BAULUZ, A., Y MORENO, R. (2011). Fotoperiodistas de guerra españoles. Madrid: Ministerio de Defensa y Turner.

BECKER, H. (1974). Photography and Sociology. American Etnography Quasimonthly. http://tinyurl.com/pm7y4rj

BOURDIEU, P. (2003). Un arte medio. Barcelona: Editorial Gustavo Gili, S.L.

BERGER, J. (2007). Modos de ver. Barcelona: Editorial Gustavo Gili, S.L.

BERICAT, R. (2012). Imagen y Conocimiento: la incorporación de la fotografía a la investigación social. Buenastareas.com. Recuperado de http://www.buenastareas.com/ensayos/Imagen-y-Conocimiento/3789640.html

BERICAT, R. (2011). Imagen y Conocimiento: retos epistemológicos de la sociología visual. Empiria, Revista de metodología de Ciencias Sociales n ${ }^{\circ} 22,113-140$.

DE MIGUEL, J.M (2003). El ojo sociológico. REIS n ${ }^{\circ} 101,49-88$.

DE MIGUEL, J., Pinto, C. (2002). Sociología Visual Madrid: CIS.

DE MIGUEL, J. M., PONCE, O. G. (1994). Para una sociología de la fotografía. REIS n $\mathrm{n}^{\circ} 84,83-124$

ELVIRA, P. (2011). La guerra civil española. Imágenes para la historia. Madrid: Editorial Lunwerg.

FREUND, G. (2011). La fotografía como documento social. Barcelona: Editorial Gustavo Gili, S.L.

MITCHELL, W.J.T (2009). Teoría de la imagen: ensayos sobre representación verbal y visual. Madrid: Ediciones Akal S.A.

PRÄKEL, D. (2007). Composición. Barcelona: Blume.

RIEGO, B. (2001). La construcción social de la realidad a través de la fotografía y el grabado informativo en la España del siglo XIX. Santander: Servicio de publicaciones de la Universidad de Cantabria. 
ROSA, I. (2013). Biblioteca de Fotógrafos Españoles: José Cendón. Madrid: La Fábrica Editorial.

SERRANO, C. (1987). Robert Capa. Cuadernos de Guerra en España 1936-1939. Valencia: Edicions Alfons el Magnànim, Institució Valenciana d'Estudis i Investigació.

SONTAG, S. (2014). Sobre la fotografía. Barcelona: Penguin Random House Grupo Editorial S.A.

SZARKOWSKI, J. (1978). Mirrors and Windows American Photography since 1960. MoMA. http://tinyurl.com/ocghg7d

VALLE GASTAMINZA, F. (2002) Dimensión documental de la fotografía. Congreso Internacional sobre Imágenes e Investigación Social. México DF. http://eprints.rclis.org/7277/

VALLE GASTAMINZA, F. (1993). El análisis documental de la fotografía. Cuadernos de documentación multimedia $\mathrm{n}^{\mathrm{0}} 2$ 2. Versión 2010 https://fvalle.wordpress.com/el-analisis-documental-de-la-fotografia/

VALLE GASTAMINZA, F. (1999). Manual de documentación fotográfica. Madrid: Editorial Síntesis. 